\title{
Rural-to-Urban Migration: Socioeconomic Status But Not Acculturation was Associated with Overweight/Obesity Risk
}

\author{
Angela Hilmers ${ }^{1,7} \cdot$ Antonio Bernabé-Ortiz $^{2,3} \cdot$ Robert H. Gilman $^{1,2,4}$. \\ Ann Y. McDermott ${ }^{1} \cdot$ Liam Smeeth $^{5} \cdot$ J. Jaime Miranda ${ }^{2,6}$
}

Published online: 19 June 2015

(c) The Author(s) 2015. This article is published with open access at Springerlink.com

\begin{abstract}
To investigate whether socioeconomic status (SES) and acculturation predict overweight/obesity risk as well as the mediating effect of physical activity (PA) in the context of internal migration. Cross-sectional study of 587 rural-to-urban migrants participating in the PERU MIGRANT study. Analyses were conducted using logistic regression and structured equation modeling. Interaction effects of SES and acculturation were tested. Models were controlled for age, gender and education. Only SES was a significant predictor of overweight/obesity risk. Lower SES decreased the odds of being overweight/obese by $51.4 \%$. This association did not vary by gender nor was it explained by PA. Mechanisms underlying the relationship between SES and overweight/obesity may differ depending on the geographic location and sociocultural context of the population studied. Research on internal migration and health would benefit from the development of tailored
\end{abstract}

Angela Hilmers

angelcaes@hotmail.com; ahilmer1@jhu.edu

1 Department of International Health, Johns Hopkins Bloomberg School of Public Health, Baltimore, MD, USA

2 CRONICAS Center of Excellence in Chronic Diseases, Universidad Peruana Cayetano Heredia, Lima, Peru

3 Epidemiology Unit, School of Public Health and Administration, Universidad Peruana Cayetano Heredia, Lima, Peru

4 Área de Investigación y Desarrollo, A.B. PRISMA, Lima, Peru

5 Faculty of Epidemiology and Population Health, London School of Hygiene and Tropical Medicine, London, UK

6 Department of Medicine, School of Medicine, Universidad Peruana Cayetano Heredia, Lima, Peru

75539 Carew St., Houston, TX 77096, USA acculturation measures and the evaluation of exploratory models that include diet.

Keywords Migration - Acculturation - Socioeconomic status · Physical activity · Latin America

\section{Background}

Overweight and obesity are recognized global public health problems and substantial contributors to the burden of chronic health conditions such as diabetes, cardiovascular diseases, and certain forms of cancer [1,2]. Once perceived as a public health issue restricted to industrialized societies, rapid increases in the rates of overweight/obesity and related co-morbidities are now widely documented in lowand middle-income countries (LMIC) [3-6].

Migrants constitute a distinctive and vulnerable population that, in general and compared to non-migrants, display disadvantaged risk factor profiles and an increased prevalence of non-communicable diseases [7, 8]. Studies with adult immigrants suggest that the observed increased in overweight/obesity risk in this population can be attributed to low socioeconomic status (SES) and greater acculturation levels $[9,10]$. Immigrants who live below official poverty thresholds were more likely to have suboptimal diets and to report lower levels of physical activity (PA) $[11,12]$.

The association between acculturation-when one culture adopts the behaviors and beliefs of another-and unhealthy dietary behaviors such as low consumption of fruits and vegetables and higher intakes of saturated fat has been consistently reported in the literature' [13] but the impact of acculturation on PA is less clear $[14,15]$. This may be attributed to differences in the type of measures 
used to assess acculturation, and the lack of adjustment of confounding variables such as SES and gender [16, 17]. Length of residence, age at migration, and second language proficiency have been previously employed as proxy acculturation measures to examine migration-related changes in lifestyle habits [18-20] However, acculturation is a complex and multidirectional phenomenon that is difficult to quantify by simple static proxy indicators [21]. Acculturation goes well beyond language use and preference; it also involves a behavioral component, i.e. attitudes and values, which can vary across life domains and contexts [22]. Gender is a largely overlooked factor that shapes both migration and acculturation. Gender variations in the process of acculturation may occur due to lifestyle differences or unique responses to social, economic and behavioral risk factors. [23-25] Furthermore, the trajectory of PA after migration is likely complex with males and females possibly displaying distinct PA patterns with increasing acculturation [14]. Finally, there is an interactive effect between SES and acculturation that should be considered when examining the impact of acculturation on health behaviors [16].

As with country-to-country migration, within country rural-to-urban migration may also be associated with the loss of traditional and protective habits, and the adoption of unhealthy behaviors that are prominent in the host environment $[26,27]$. Nevertheless, its association with overweight/obesity risk remains under-researched, let alone addressed, thereby limiting opportunities to better understand immigrant health differentials and their link to health and gender disparities among the ethnic populations.

Using data from a representative sample of rural-tourban migrants within one country, we attempt to expand our knowledge of the impact of internal migration on health as well as address some of the limitations of previous studies. We consider gender while exploring the association between sociocultural factors and overweight/ obesity, improve on research that use single item measures of acculturation, and create a hypothetical model that incorporates PA.

\section{Methods}

\section{Study Design}

A cross-sectional study was conducted using data from PERU MIGRANT (PEru's Rural to Urban MIGRANTs). The PERU MIGRANT study was designed to investigate differences in specific cardiovascular disease risk factors between migrant and non-migrant groups [28]. Data used in this study were limited to the migrant group participants and collected in 2007. Ethical approval was obtained from
Universidad Peruana Cayetano Heredia in Peru and London School of Hygiene and Tropical Medicine in the United Kingdom. All study participants provided written informed consent.

\section{Subjects and Setting}

Participants were rural-to-urban migrants born in Ayacucho-a rural state in the Andean region of Peru-who later migrated to and were permanently living in an urban area of Lima. Participants were a product of the mass migration phenomena that occurred since the 1980s when patterns of migration in the Andean region changed dramatically mostly due to increasing political unrest and violence [28]. This process of forced migration provides a unique opportunity to assess the impact of SES and acculturation on overweight/obesity risk in a wide variety of migrants, not only among those who "chose" to migrate. Pregnant women were excluded because of gestational weight gain, as well as individuals suffering from mental disorders as this could affect the accuracy of their responses and the completeness of the survey.

\section{Conceptual Model}

A conceptual model was developed based on empirical evidence relating sociocultural influences to the dependent variable, overweight/obesity (Fig. 1) [29, 30]. The model was grounded in Bandura's Social Cognitive Theory which postulates that a dynamic interplay of personal factors (e.g., acculturation), agent's behavior (e.g., PA) and social environment (e.g., SES) create interactions that result in specific outcomes (e.g., overweight/obesity) [31]. SES and acculturation were hypothesized to have (1) direct effects on overweight/obesity; and (2) indirect effects on overweight/obesity through PA. In this context, PA represents an intermediary process that leads from the independent variables (SES and acculturation) to the dependent variable (overweight/obesity). An illustrative example is the higher prevalence of overweight/obesity observed in developed areas among migrants with lower SES as a result of

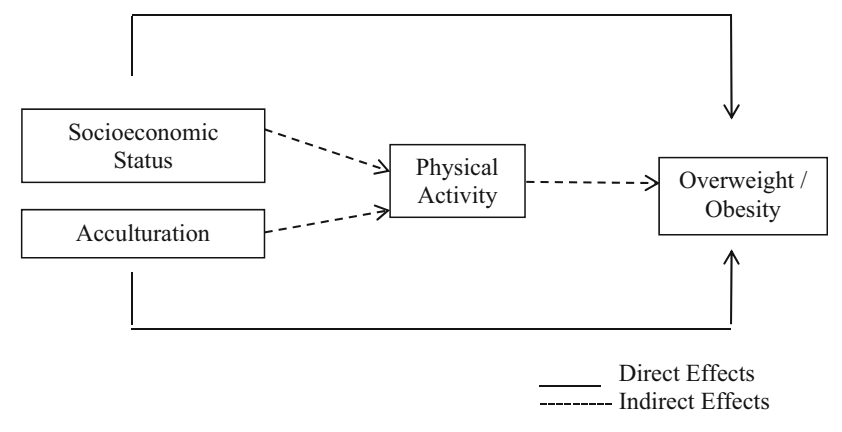

Fig. 1 Conceptual model 
reduced levels of PA [32, 33]. Associations between sociocultural factors and overweight/obesity were hypothesized to vary by gender based on literature addressing gender disparities related to income and cultural factors $[24,25]$.

\section{Measures}

\section{Demographic and Socioeconomic Characteristics}

Trained community field workers administered a demographic survey to all eligible participants. Information on age, gender, educational level, household income, and asset possession were collected. Place of birth and setting (rural or urban) was assessed to establish a rural-to-urban migration pattern. Rural-to-urban migration was defined as the movement of individuals from the countryside into the cities, often the metropolitan cities of a country [34]. A multideprivation index, a more reliable indicator of poverty than income [35], was estimated based on the aggregated number of deprivations in education (none or incomplete primary education), household income ( $<$ US\$150 per month) and asset possession (lowest tertile of possessions weighted asset index) per individual. As we continue through this paper we will use the term SES to refer to an individual's "deprivation index". Participants showing deprivation in more than two of the given deprivation indicators were considered of low SES while those presenting none to one deprivation indicators were classified as high SES.

\section{Anthropometrics}

Height and weight were obtained at a local clinic by trained study staff. Height was measured to the nearest $0.1 \mathrm{~cm}$ using a stadiometer and standard tools. Body weight with light clothing was measured to the nearest $0.05 \mathrm{~kg}$ using an electronic, self-calibrating digital scale (SECA 940 Model scale). Body mass index (BMI) was calculated using the formula [weight (kg)/height ( $\mathrm{m} \mathrm{[2]} \mathrm{)].} \mathrm{Overweight} \mathrm{and} \mathrm{obe-}$ sity were defined as BMI $\geq 25 \mathrm{~kg} / \mathrm{m}$ [2] and BMI $\geq 30 \mathrm{~kg} /$ $\mathrm{m}$ [2] respectively for men and women according to current accepted guidelines. [36] In this study, the overweight and obesity groups were combined to insure sufficient power and enable us to focus on all individuals at an "unhealthy weight" represented by a BMI $\geq 25 \mathrm{~kg} / \mathrm{m}$ [2].

\section{Physical Activity}

The short version of the International Physical Activity Questionnaire (IPAQ-SF) was employed to assess PA in the past 7 days. The IPAQ-SF is considered a cost-efficient method for PA activity surveillance in different populations [37] Reliability $(\mathrm{M}=0.80)$ and validity $(\mathrm{M}=0.30)$ correlations of this instrument are comparable to other self-report instruments [38]. Responses were converted to Metabolic Equivalent Task minutes per week (MET - $\mathrm{min} / \mathrm{wk}$ ) and scores were categorized into moderate-to-high and low PA. Moderate-to-high PA was defined as five or more days of any combination of walking and moderate or vigorous intensity activities achieving at least 600-3000 MET minutes per week [37]. Low PA was represented by $<150$ MET minutes in 1 week.

\section{Acculturation}

Ten items were adapted from existing acculturation scales with evidence of good reliability and validity to assess [39, 40]: (1) language use and proficiency (7 items); (2) ethnicsocial relations (2 items); and (3) media use (1 item). Participants were asked to name the first language they learned to speak as well as their competence and preferences for speaking Spanish or Quechua (language spoken primarily in the Andes) in their interpersonal relationships (e.g., with children, spouse and friends). Ethnic-social relations captured attitudes regarding traditional and cultural activities and the preferred ethnicity of those with whom the participant interacts. Finally, one item measured use and preference of Spanish or Quechua language media.

The acculturation items were rated in a 4-point and 5point scales. Responses were transformed to 1 (responses favoring Spanish) or 0 (responses favoring Quechua) following the method of transformation described by Deyo et al. [39]. A continuous score of acculturation was calculated by summing all transformed item-responses. Scores ranged from 0 to 10 with higher scores indicating higher acculturation levels.

\section{Statistical Analysis}

Student $t$ test (for continuous variables) and Chi-square test (for categorical variables) were conducted to examine differences in participant characteristics by weight status. Logistic regression investigated associations between the two independent variables and overweight/obesity. All models were adjusted for age, education and PA. Because SES may be confounded with acculturation, the interactive effect between SES and acculturation was tested and the model was adjusted for SES or acculturation depending on the associations examined.

\section{Structural Equation Modeling (SEM)}

Data were analyzed using path models, which is a special case of SEM with mean-adjusted weighted least squares 
estimation. The primary outcome variable for this analysis was the dichotomous variable overweight/obesity status (i.e., overweight/obese $=1$ versus non-overweight/obese $=0$ ). The estimated multi-deprivation index was dichotomized into low $\mathrm{SES}=1$ and high $\mathrm{SES}=0$. Acculturation was included as a continuous variable in the model.

SES and acculturation level were hypothesized to have direct and mediating effects on overweight/obesity through PA (Fig. 1). Solid arrows indicate a direct path while dashed arrows indicate an indirect effect. SME analyses also explored whether gender moderated the strength or direction (i.e., positive or negative) of the relationship between SES or acculturation and overweight/obesity. Analyses were conducted in Mplus (version 6.11, 1998-2011, Muthén \& Muthén, Los Angeles, CA) and in Statistical Analysis Systems (version 9.3, 2011, SAS Institute Inc., Cary, NC).

\section{Results}

\section{Description of Participants}

A total of 587 participants were included in the analysis. The mean age of the sample was 47.8 years $(\mathrm{SD} \pm 11.7)$; $52 \%$ were females; and $67 \%$ were overweight/obese (Table 1). Most participants reported engaging in moderate to high PA levels. When comparing overweight/obese to non-overweight/obese individuals, no significant differences were observed in SES, PA or acculturation levels.

\section{Sociocultural Factors and Overweight/Obesity}

The strongest predictor of overweight/obesity was SES $(\mathrm{OR}=0.486 ; p=0.008)$. Acculturation was not significantly associated with overweight/obesity in either gender group. No significant interactions were observed between gender and SES or gender and acculturation ( $p=0.8932$ and $p=0.1763$, respectively). Interaction effects between SES and acculturation were not significant $(p=0.67)$. Holding acculturation, gender, age, and education constant, the odds of being overweight/obese were $51.4 \%$ lower for rural-to-urban migrants with low SES compared to those from higher SES. Similar associations were observed before and after adjusting for PA (Table 2). A trend toward significance was observed when analyses were conducted separately by gender (females $\mathrm{OR}=0.535 ; p=0.07$; males $\mathrm{OR}=0.444 ; p=0.06$ ) (results not shown).

\section{Structural Equation Modeling}

The results showed the data fitted the hypothesized model when acculturation and SES were modeled as correlates (Table 3).
Table 4 displays the regression coefficients $\beta$ and standard errors for each significant path. The empirical model manifested the following pathways: (1) SES had a direct effect on overweight/obesity independent of gender. Ruralto-urban migrants with low SES were less likely to be overweight/obese than their wealthier counterparts; (2) PA was not a significant mediator of the relationship between SES and overweight/obesity; and (3) acculturation level was not associated with overweight/obesity in this population.

\section{Discussion}

Contrary to emerging evidence suggesting a higher prevalence of overweight/obesity in groups with the lowest SES, this study showed that, among rural-to-urban migrants, SES was positively associated with their BMI status. Similar associations have been reported in a number studies with non-migrant groups in Peru [41], Brazil [42], Ecuador [43], and Colombia [44].

Acculturation was not associated with overweight/obesity in our sample. An appropriate instrument to measure acculturation among within country rural-to-urban migrants has not been developed. The set of items chosen from two separate instruments developed for and validated among Hispanic immigrants in the United States were believed to have universal applicability. However, the lack of association between acculturation and overweight/obesity may suggest that the unique cultural characteristics of our sample may require a group-specific approach to acculturation. A major challenge for future studies in this area is to capture these unique cultural dimensions when examining the impact of acculturation on overweight/ obesity.

A majority of migrants in this study reported moderateto-high PA levels independent of their gender. In high income countries, immigrants, particularly those with low SES, are more likely to report lower levels of PA [45]. Urban planning, perceived crime, traffic safety, and lack of access to recreational equipment and programs that support an active lifestyle have a considerable impact on their activity patterns [46-48] Our findings suggest that in LMIC, migrants who have moved from rural-to-urban areas seem to lead more active lifestyles probably due to characteristics of their jobs that may require constant physical mobility and the need to be more physically active to fulfill the necessities of everyday living, e.g., walking to different locations. Differences in PA by SES were not explored. However, past research among non-migrant and migrant groups in similar settings has reported an inverse association between SES and PA levels [49]. This further supports the importance of considering the socioeconomic 
Table 1 Baseline Characteristics of the Study Population by Weight Status

\begin{tabular}{|c|c|c|c|c|}
\hline & Total $(\mathrm{N}=587)$ & Non-overweight/Obese $(\mathrm{n}=192)$ & Overweight/obese $(\mathrm{n}=395)$ & $p$ value $^{\mathrm{a}}$ \\
\hline Age (mean, $S D)$ & $47.78(11.66)$ & $47.27(12.78)$ & $47.91(10.95)$ & 0.55 \\
\hline \multicolumn{5}{|l|}{ Gender $(\%)$} \\
\hline Female & $309(52.64)$ & $85(44.27)$ & $224(56.71)$ & \multirow[t]{2}{*}{$<0.01$} \\
\hline Male & $278(47.36)$ & $107(55.73)$ & $171(43.29)$ & \\
\hline \multicolumn{5}{|l|}{ Education level (\%) } \\
\hline None/some elementary school & $181(30.89)$ & $54(28.13)$ & $127(32.23)$ & \multirow[t]{3}{*}{$<0.001$} \\
\hline Elementary school/some high school & $225(38.40)$ & $63(32.81)$ & $162(41.12)$ & \\
\hline High school and more & $180(30.72)$ & $75(39.06)$ & $105(26.65)$ & \\
\hline \multicolumn{5}{|l|}{ Multi-deprivation index, $n(\%)^{\mathrm{b}}$} \\
\hline Two or more deprivations (Low SES) & $106(18.06)$ & $42(21.88)$ & $64(16.20)$ & \multirow[t]{2}{*}{0.09} \\
\hline None to one deprivation (High SES) & $481(81.94)$ & $150(78.13)$ & $331(83.80)$ & \\
\hline Acculturation $(\text { mean, } S D)^{\mathrm{c}}$ & $7.47(1.5)$ & $7.45(1.52)$ & $7.49(1.47)$ & 0.76 \\
\hline \multicolumn{5}{|l|}{ Physical Activity, $n(\%)^{\mathrm{d}}$} \\
\hline Moderate/high & $408(70.34)$ & $133(71.12)$ & $275(69.97)$ & \multirow[t]{2}{*}{0.78} \\
\hline Low & $172(29.66)$ & $54(28.88)$ & $118(30.03)$ & \\
\hline
\end{tabular}

Bold values indicate statistical significance $(\alpha=0.05)$

Values are mean $\pm \mathrm{SD}$ or $\mathrm{n}(\%)$. Non-overweight $/$ obese $=\mathrm{BMI}<25 \mathrm{~kg} / \mathrm{m}^{2}$; Overweight $/$ obese $=\mathrm{BMI} \geq 25 \mathrm{~kg} / \mathrm{m}^{2}$

${ }^{a}$ Student $t$ test for continuous variables (age, acculturation). Chi square test for categorical variables (gender, education, multi-deprivation index, physical activity)

b Aggregated number of deprivations based on the sum of the following deprivation indicators: education (none or incomplete primary education), income (household income $<$ US\$150 per month) and assets (lowest tertile of possessions weighted asset index) in the same individual

${ }^{c}$ Measured by 10-item acculturation scale. Scores ranged from 0-10 with higher scores indicating higher acculturation

${ }^{\mathrm{d}}$ Moderate-to-high PA $=$ at least 600-3000 MET minutes/week. Low PA $=$ less than 150 MET minutes in 1 week

Table 2 Logistic regression analysis predicting obesity in migrants

\begin{tabular}{lllll}
\hline & Odds ratio & $95 \%$ CI & $\chi^{2}$ & $p$ value \\
\hline Socioeconomic status $^{\mathrm{a}}$ & 0.486 & $0.285-0.828$ & 7.0498 & $\mathbf{0 . 0 0 7 9}$ \\
Acculturation $^{\mathrm{b}}$ & 1.087 & $0.949-1.246$ & 1.4491 & 0.2287 \\
\hline
\end{tabular}

Bold values indicate statistical significance $(\alpha=0.05)$

${ }^{a}$ Adjusted for age, gender, education and acculturation

b Adjusted for age, gender, education and socioeconomic status

and cultural contexts in which behavioral adoption and practice takes place. Results of the mediation analysis indicate that the direct effect of SES on overweight/obesity was not explained by PA. Whereas this could be partly attributable to the use of self-reported data, contextual factors such as the social and physical environment already discussed need to be considered.

\section{Strengths and Limitations}

Strengths of this study include a representative sample size, the use of a summary measure of acculturation and the development of a deprivation index to assess SES. Compared to other migrant studies, a potential for selection bias was most likely reduced as mass migration from Andean communities such as Ayacucho (rural setting) to Lima (urban setting) was driven by guerrilla violence, political instability, and deepening poverty [50]. A single acculturation score that accounts for different characteristics often clustered within an individual may give a more accurate representation of acculturation than each indicator independently. A deprivation index is considered a more reliable indicator of SES than household income [35].

Limitations include the cross-sectional design that prevents causal interpretation of the relationship between sociocultural factors and overweight/obesity. Because of the limited number of individuals in the obesity category and to maintain sufficient study power, we did not analyze 
Table 3 Summary of fit indices for path models of SES and acculturation

\begin{tabular}{|c|c|c|c|c|c|c|c|c|c|c|}
\hline Models & $\chi^{2}$ & $D f$ & $\mathrm{P}$ & CFI & TLI & RMSEA & WRMR & $\Delta \chi^{2}$ & $\Delta d f$ & $p$ value \\
\hline \multicolumn{11}{|l|}{ Acculturation } \\
\hline All participants & 1.39 & 4 & 0.85 & 1.00 & 1.44 & 0.00 & 0.296 & & & \\
\hline \multicolumn{11}{|l|}{ Multi-group process } \\
\hline $\mathrm{M}_{1}$ no constrains & 3.64 & 6 & 0.72 & 1.00 & 1.75 & 0.00 & 0.560 & & & \\
\hline $\mathrm{M}_{2}$ all path loadings constrained & 8.14 & 12 & 0.77 & 1.00 & 1.61 & 0.00 & 0.844 & 4.506 & 6 & 0.619 \\
\hline $\mathrm{M}_{3}$ all variances constrained & 57.04 & 14 & 0 & 0.8 & 0.57 & 0.10 & 1.509 & 48.891 & 2 & $<0.0001$ \\
\hline \multicolumn{11}{|l|}{ Socioeconomic status } \\
\hline All participants & 2.67 & 4 & 0.61 & 1.00 & 1.22 & 0.00 & 0.443 & & & \\
\hline \multicolumn{11}{|l|}{ Multi-group process } \\
\hline $\mathrm{M}_{1}$ no constrains & 4.34 & 6 & 0.63 & 1.00 & 1.53 & 0.00 & 0.619 & & & \\
\hline $\mathrm{M}_{2}$ all path loadings constrained & 9.04 & 12 & 0.70 & 1.00 & 1.47 & 0.00 & 0.895 & 4.702 & 6 & 0.581 \\
\hline $\mathrm{M}_{3}$ All variances constrained & 59.03 & 14 & 0 & 0.79 & 0.55 & 0.11 & 1.538 & 49.988 & 2 & $<0.0001$ \\
\hline
\end{tabular}

Bold values indicate statistical significance $(\alpha=0.05)$

RMSEA: $<0.05$ (good), $<0.08$ (acceptable); CFI/TLI: $>0.95$ (great), $>0.93$ (better), $>0.90$ (good)

Table 4 Direct and indirect effects of SES and acculturation on obesity

\begin{tabular}{lrr}
\hline Independent variables & \multicolumn{1}{l}{ Direct effects } & \multicolumn{1}{c}{ Indirect effects $^{\mathrm{b}}$} \\
\hline Socioeconomic status $^{\mathrm{c}}$ & $-0.495(\boldsymbol{p}=\mathbf{0 . 0 0 2})$ & $0.003(p=0.719)$ \\
Acculturation $^{\mathrm{d}}$ & $0.048(p=0.251)$ & $-0.002(p=0.607)$ \\
\hline
\end{tabular}

Dependent variable $=$ overweight/obesity status (overweight/ obese $=1$ vs. non overweight/obese $=0$ )

${ }^{\mathrm{a}}$ Mediator $=$ Physical activity; ${ }^{\mathrm{b}}$ Low $\mathrm{SES}=1$; high $\mathrm{SES}=0$. Adjusted for age, gender, education and acculturation; ${ }^{\mathrm{c}}$ Adjusted for age, gender, education and deprivation index

the data for each group separately. The adapted acculturation scale used in this study may not be applicable to our population. Some of the items were scored at different scales for which reliability could not be calculated. The magnitude of the mediation effect may have differed if objective measures of PA were employed. Over-reporting of PA remains an important limitation among studies using self-reported measures of PA and the IPAQ-SF is no exception [51]. Finally, our hypothetical model did not include other possible mediators such as diet, smoking, emotional factors, and lack of sleep.

The results of this study add to the current understanding of the impact of sociocultural dynamics on the global overweight/obesity epidemic but leave many questions unanswered. It appears that efforts toward global overweight/obesity prevention should be tailored to community context, particularly socio-demographic composition, characteristics of the built environment, and previous and current health behavior performance. Given the complexity and interaction of these factors, a "one size fits all" for successful overweight/obesity prevention strategies seems unlikely. For instance, modifications to dietary intake, chronic stress or habitual sleep patterns may be more effective in our population than increasing energy expenditure. In addition, considering that global gender disparities in obesity exist, gender-specific or gender-tailored solutions may be also necessary.

This study is one of very few which has attempted to investigate the potential pathways through which sociocultural factors and overweight/obesity may be linked among migrants from rural-to-urban areas in LMIC. Findings of a positive association between SES and overweight/obesity suggest that mechanisms underlying this relationship may differ depending on the geographic setting (i.e., international migrants from low socioeconomic backgrounds are more likely to be obese in high income countries probably due to high levels of urbanization, easy access to transportation and changes in their dietary habits and the sociocultural context (i.e., changes in cultural beliefs and values around PA and/or diet may be more apparent among international migrants than internal migrants as they are exposed to cultural and social stresses that markedly differ from their own) in which migrants are embedded. The role of acculturation as a risk factor for the development of non-communicable diseases needs to be better understood. Future research should further explore the directional effects of acculturation and overweight/ obesity in this population. However, this should be preceded by the development of a culturally valid acculturation scale in order to be fully applicable to internal migrants in LMIC.

Acknowledgments The authors are indebted to Dr. Karen Cullen and Dr. Tzu-An Chen from Baylor College of Medicine, Houston, TX for their invaluable contribution to the analysis and preparation of this 
manuscript. ABO, RHG, JJM and the CRONICAS Center of Excellence in Chronic Diseases at UPCH are funded by the National Heart, Lung and Blood Institute (NHLBI), National Institutes of Health, Department of Health and Human Services, under contract number HHSN268200900033C. The PERU MIGRANT Study was funded by a Wellcome Trust Masters Research Training Fellowship and a Wellcome Trust PhD Studentship to JJM (GR074833MA). LS is supported by a Wellcome Trust Senior Research Fellowship in Clinical Science.

Conflict of interest The authors declare no conflict of interest.

Open Access This article is distributed under the terms of the Creative Commons Attribution 4.0 International License (http://creativecommons.org/licenses/by/4.0/), which permits unrestricted use, distribution, and reproduction in any medium, provided you give appropriate credit to the original author(s) and the source, provide a link to the Creative Commons license, and indicate if changes were made.

\section{References}

1. Finucane MM, Stevens GA, Cowan MJ, et al. National, regional, and global trends in body-mass index since 1980: systematic analysis of health examination surveys and epidemiological studies with 960 country-years and 9.1 million participants. Lancet. 2011;377(9765):557-67.

2. Kelly T, Yang W, Chen CS, Reynolds K, He J. Global burden of obesity in 2005 and projections to 2030. Int J Obes (Lond). 2008;32(9):1431-7.

3. Institute of Medicine. Promoting cardiovascular health in the developing world: a critical challenge to achieve global health. Washington, D.C.: National Academies Press; 2010.

4. Aballay LR, Eynard AR, Díaz MP, Navarro A, Muñoz SE. Overweight and obesity: their relationship to metabolic syndrome, cardiovascular disease, and cancer in South America. Nutr Rev. 2013;71(3):168-79.

5. Popkin BM, Adair LS, Ng SW. Global nutrition transition and the pandemic of obesity in developing countries. Nutr Rev. 2012; 70(1):3-21.

6. Subramanian SV, Perkins JM, Özaltin E, Davey-Smith G. Weight of nations: socioeconomic analysis of women in low- to middleincome countries. Am J Clin Nutr. 2011;93(2):413-21.

7. Venters H, Gany F. African immigrant health. J Immigr Minor Health. 2011;13(2):333-44.

8. Asgary R, Ramesh N, Swedish KA, Smith CL, Sckell B, Doorley S. Communicable and non-communicable diseases among recent immigrants with implications for primary care: a comprehensive immigrant health approach. J Immigr Minor Health. 2011;13(6): 990-5.

9. Delavari M, Sonderlund AL, Swinburn B, Mellor D, Renzaho A. Acculturation and obesity among migrant populations in high income countries: a systematic review. BMC Public Health. 2013;13:458.

10. Fitzgerald N. Acculturation, Socioeconomic status, and health among Hispanics. NAPA bulletin. Special issue: anthropological perspectives on migration and health. 2010; 34(1):28-46.

11. Weiss JW, Rubin D, Gomel JN. Physical activity among newly immigrated Latino adults. Californian J Health Promot 2009; 7(Special Issue):131-38.

12. Buttenheim A, Goldman N, Pebley AR, Wong R, Chung C. Do Mexican immigrant "import" social gradients in health to the US? Soc Sci Med. 2010;71(7):1268-76.
13. Ayala G, Baquero B, Klinger S. A systematic review of the relationship between acculturation and diet among latinos in the United States: implications for future research. J Am Diet Assoc. 2008;108(8):1330-44.

14. Berrigan D. Physical activity and acculturation among adult hispanics in the United States. Res Q Exerc Sport. 2006;77(2): 147-57.

15. Evenson KR, Sarmiento OL, Ayala GX. Acculturation and physical activity among North Carolina Latina immigrants. Soc Sci Med. 2004;59(12):2509-22.

16. Afable-Munsuz A, Ponce NA, Rodriguez M. Pérez- Stable EJ. Immigrant generation and physical activity among Mexican, Chinese and Filipino adults in the US. Soc Sci Med. 2010; 70(12): 1997-2005.

17. Hunt LM. Health research: what's culture got to do with it? Lancet. 2005;366(9486):617-8.

18. Lara M, Gamboa C, Kahramanian MI, Morales LS, Bautista DEH. Acculturation and Latino health in the United States: a review of the literature and its sociopolitical context. Annu Rev Publ Health. 2005;26:367-97.

19. Redfield R, Linton R, Herskovits MJ. Memorandum for the Study of Acculturation. Am Anthropol. 1936;38:149-52.

20. Colón-López V, Haan MN, Aiello AE, Ghosh D. The effect of age at migration on cardiovascular mortality among elderly Mexican immigrants. Ann Epidemiol. 2009;19(1):8-14.

21. Negy C, Woods DJ. The importance of acculturation in understanding research with Hispanic-Americans. Hisp J Behav Sci. 1992;14(2):224-47.

22. Berry JW. Conceptual approaches to acculturation. In: Chun KM, Organista PB, Marín G, editors. Acculturation: advances in theory, measurement and applied research. 2003; pp. 17-Washington, DC: American Psychological Association. Available at: http://dx.doi.org/10.1037/10472-004.

23. Donato KM and Patterson E. "Women and men on the move: undocumented border crossing." In: Durand J, Massey DS, editors. Crossing the border: research from the Mexican migration project. New York: Russell Sage Foundation; 2004. p 111-30.

24. Hondagneu-Sotelo P, Cranford C. "Gender and Migration."In: Chafetz JS, editor. Handbook of the sociology of gender. New York: Klewer Academic/Plenum Publishers; 1999. Pp. 105-26.

25. Kanaiaupuni SM. Reframing the migration question: an analysis of men, women, and gender in Mexico. Soc Forces. 2000;78(4): 1311-47.

26. Ebrahim S, Kinra S, Bowen L, Andersen E, Ben-Shlomo Y, et al. The effect of rural-to-urban migration on obesity and diabetes in India: a cross-sectional study. PLoS Med. 2010;7(4):e1000268.

27. Abraido-Lanza AF, Chao MT, Florez KR. Do healthy behaviors decline with greater acculturation? Implications for the Latino mortality paradox. Soc Sci Med. 2005;61(6):1243-55.

28. Miranda JJ, Gilman RH, García HH, Smeeth L. The effect on cardiovascular risk factors of migration from rural to urban areas in Peru: PERU MIGRANT Study. BMC Cardiovas Disord. 2009;9:23.

29. Sallis J, Owen N, Fisher EB. Ecological models of health behaviour. In: Glanz K, Rimer BK and Viswanath K, editords. Health behavior and health education: theory, research, and practice. 4th ed. ed. San Francisco: Jossey-Bass; 2008.

30. Pérez-Escamilla R, Putnik P. The role of acculturation in nutrition, lifestyle, and incidence of type 2 diabetes among Latinos. J Nutr. 2007;137(4):860-70.

31. Bandura A. Social cognitive theory: an agentive perspective. Annu Rev Psychol. 2001;52:1-26.

32. Fitzgerald N. Acculturation, socioeconomic status, and health among Hispanics. NAPA bulletin. Special issue: anthropological perspectives on migration and health. 2010; 34(1):28-46. 
33. Weiss JW, Rubin D, Gomel JN. Physical activity among newly immigrated Latino adults. Californian J Health Promot 2009; 7(Special Issue):131-38.

34. Saracoglu DS and Roe TL. Rural-urban migration and economic growth in developing Countries, 2004 Meeting Papers 241, Society for Economic Dynamics.

35. Heikkila M, Moisio P, Ritakallio VM, Bradshaw J, Kuivalainen S, Hellsten K, Kajoja J. Poverty policies, structures and outcomes in the EU 25. Report to the Fifth European round table on poverty and social exclusion, stakes Helsinki, Finland, 2006. Available at: http://www.stm.fi/Resource.phx/eng/subjt/inter/eu2006/round/ round1.htx.i1153.pdf.

36. World Health Organization. Obesity: preventing and managing the global epidemic. Report of a WHO Consultation. WHO Technical Report Series 894. Geneva: World Health Organization, 2000.

37. Craig CL, Marshall AL, Sjöström M, et al. International physical activity questionnaire: 12-Country reliability and validity. Med Sci Sports Exerc. 2003;35(8):1381-95.

38. Sallis JF, Saelens BE. Assessment of physical activity by selfreport: status, limitations and future directions. Res Q Exerc Sport. 2000;71:S1-14.

39. Deyo RA, Diehl AK, Hazuda H, Stern MP. A simple languagebased acculturation scale for Mexican Americans: validation and application to health care research. Am J Public Health. 1985;75(1):51-5.

40. Marín G, Saboga F, VanOss Marín B, Otero-Sabogal F, PérezStable EJ. Development of a short acculturation scale for Hispanics. Hispanic J Behav Sci. 1987;9:183-205.

41. Álvarez-Dongo D, Sánchez-Abanto J, Gómez-Guizado G, Tarqui-Mamani C. Sobrepeso y obesidad: prevalencia y determinantes sociales del exceso de peso en la población peruana (2009-2010). [Overweight and obesity: prevalence and determining social factors of overweight in the Peruvian population
(2009-2010)]. Rev Peru Med Exp Salud Publica 2012; 29(3): 303-13.

42. Monteiro CA, Conde WL, Popkin BM. Income-specific trends in obesity in Brazil: 1975-2003. Am J Public Health. 2007;97(10): 1808-12.

43. Bernstein A. Emerging patterns in overweight and obesity in Ecuador. Rev Panam Salud Publica. 2008;24(1):71-4.

44. McDonald CM, Baylin A, Arsenault JE, Mora-Plazas M, Villamor E. Overweight is more prevalent than stunting and is associated with socioeconomic status, maternal obesity, and a snacking dietary pattern in school children from Bogota, Colombia. J Nutr. 2009;139(2):370-6.

45. Dogra S, Meisner BA, Ardern CI. Variation in mode of physical activity by ethnicity and time since immigration: a cross-sectional analysis. Int J Behav Nutr Phys Act. 2010;7:75.

46. Kaczynski AT, Potwarka LR, Saelens BE. Association of park size, distance, and features with physical activity in neighborhood parks. Am J Public Health. 2008;98(8):1451-6.

47. Ferreira I, Van der Horst K, Wendel-Vos W, Kremers S, Van Lenthe FJ, Brug J. Environmental correlates of physical activity in review: a review and update. Obes Rev. 2006;8(2):129-54.

48. Romero AJ. Low-incomeneighborhood barriers and resources for adolescents' physical activity. J Adolesc Health. 2005;36(3): 253-9.

49. Masterson-Creber RM, Smeeth L, Gilman RH, Miranda JJ. Physical activity and cardiovascular risk factors among rural and urban groups and rural-to-urban migrants in Peru: a cross-sectional study. Rev Panam Salud Publica 2010; 28(1):1-8.

50. Mayer E. Poder y violencia en los Andes. Centro de Estudios Regionales Andinos: Bartolomé de Las Casas; 1991. p. 419.

51. Lee PH, Macfarlane DJ, Lam TH, Stewart SM. Validity of the international physical activity questionnaire short form (IPAQSF): a systematic review. Int J Behav Nutr Phys Act. 2011;8:115. 